\title{
Sobre as Categorias Valor e Preço da Força de Trabalho em Marx
}

Elizeu Serra de Araujo*

Resumo: $\mathrm{O}$ artigo analisa duas questões. A primeira é se a luta de classes, além da influência que exerce sobre os movimentos do preço da força de trabalho, é capaz de influenciar a magnitude do próprio valor dessa mercadoria. A segunda é se existe possibilidade de o preço da força de trabalho situar-se, não apenas conjunturalmente, mas por longos períodos, abaixo do seu valor, e se isso não poria em xeque a vigência da lei do valor no caso da mercadoria força de trabalho. $\mathrm{Na}$ discussão de ambas as questões, a teoria do valor constitui a referência fundamental, a despeito das especificidades da força de trabalho em relação às demais mercadorias.

Palavras-chave: Valor da força de trabalho. Preço da força de trabalho. Salário. Luta de classes.

Classificação JEL: B14; J31.

On the Categories of Value and Price of Labour Power in Marx

\begin{abstract}
The article analyzes two questions. The first one is whether class struggle, besides the influence it exerts on the movements of the price of labour power, can influence the magnitude of the value itself of this commodity. The second one is whether there is possibility of the price of labour power situate not only circumstantially, but for long periods, below its value, and whether this would not call into question the validity of the law of value in the case of the commodity of labour power. In the discussion of both questions the theory of value is the fundamental reference, in spite of the specificities of labour power in relation to other commodities.
\end{abstract}

Keywords: Value of labour power. Price of labour power. Wage. Class struggle.

JEL Classification: B14; J31.

Professor do Departamento de Economia e do Programa de Pós-Graduação em Desenvolvimento Socioeconômico, Universidade Federal do Maranhão. E-mail: elizeuserra@yahoo.com 


\section{Introdução}

As formulações de Marx acerca do valor da força de trabalho têm dado margem a intensa controvérsia. Em geral, as questões discutidas estão associadas ao intento do autor de aplicar consistentemente a teoria do valor ao caso da mercadoria força de trabalho, a despeito de suas especificidades em relação às demais mercadorias.

O objetivo deste artigo consiste em analisar duas questões específicas. A primeira é se a luta de classes, além da influência que exerce sobre os movimentos do preço da força de trabalho, é capaz de influenciar a magnitude do próprio valor dessa mercadoria. A segunda é se existe possibilidade de o preço da força de trabalho situar-se, não apenas conjunturalmente, mas por longos períodos, abaixo do seu valor. Isso não poria em xeque a vigência da lei do valor no caso da mercadoria força de trabalho? Esta última questão é suscitada pela tese de Ruy Mauro Marini acerca da superexploração da força de trabalho, na medida em que o referido fenômeno é caracterizado essencialmente pela vigência de um salário médio inferior ao valor da força de trabalho.

Para encaminhar o assunto, retomamos, preliminarmente, a exposição de Marx acerca das categorias valor da força de trabalho - a determinação de sua magnitude e suas variações - e preço da força de trabalho. Esse é o objeto das seções 2 e 3 deste artigo. A seguir, na seção 4 , abordamos as questões que constituem o objeto específico do artigo, tal como indicadas acima. A seção 5 traz as principais conclusões do estudo. ${ }^{1}$

\section{A determinação da magnitude do valor da força de trabalho}

O procedimento adotado por Marx ao determinar a magnitude do valor da força de trabalho leva em conta o fato de que a força de trabalho - ou capacidade de trabalho - é uma mercadoria como qualquer outra, embora em certos aspectos se diferencie das restantes mercadorias. Assim, no capítulo 4 do livro I de O capital, ao tratar da compra e venda da força de trabalho, Marx escreve:

O valor da força de trabalho, como o de toda outra mercadoria, é determinado pelo tempo de trabalho necessário à produção, portanto também reprodução, desse artigo específico. Enquanto valor, a própria força de trabalho representa apenas determinado quantum de trabalho social médio nela objetivado. A força de trabalho só existe como disposição do indivíduo vivo. Sua produção pressupõe, portanto, a existência dele. Dada a existência do indivíduo, a produção da força de trabalho consiste em sua própria reprodução ou manutenção. Para sua manutenção, o indivíduo vivo precisa de

Ultrapassa os propósitos deste artigo tentar rastrear a evolução do pensamento de Marx acerca das questões elencadas. A discussão feita aqui toma por base a forma em que elas são tratadas em sua fase madura, especialmente em O capital e em Salário, preço e lucro. 
certa soma de meios de subsistência. O tempo de trabalho necessário à produção da força de trabalho corresponde, portanto, ao tempo de trabalho necessário à produção desses meios de subsistência ou o valor da força de trabalho é o valor dos meios de subsistência necessários à manutenção do seu possuidor. $(C, \mathrm{I} / 1, \mathrm{p} .141)^{2}$

Após a afirmação desse princípio fundamental, que, a rigor, constitui uma aplicação da sua teoria do valor ao caso da mercadoria força de trabalho, Marx especifica três elementos que, em conjunto, determinam a soma dos meios de subsistência necessários à reprodução dessa mercadoria.

Em primeiro lugar, a soma dos meios de subsistência deve ser proporcional ao volume de trabalho realizado. Assim, a determinação do valor da força de trabalho toma como referência uma quantidade determinada de meios de subsistência necessários à realização de um volume normal de trabalho:

A força de trabalho só se realiza, no entanto, mediante sua exteriorização, ela só se aciona no trabalho. Por meio de sua ativação, o trabalho, é gasto, porém, determinado quantum de músculo, nervo, cérebro etc. humanos que precisa ser reposto. Esse gasto acrescido condiciona uma receita acrescida. Se o proprietário da força de trabalho trabalhou hoje, ele deve poder repetir o mesmo processo amanhã, sob as mesmas condições de força e saúde. A soma dos meios de subsistência deve, pois, ser suficiente para manter o indivíduo trabalhador como indivíduo trabalhador em seu estado de vida normal. (C, I/1, p. 141)

O raciocínio se aplica, por um lado, à extensão da jornada de trabalho; por outro, ao grau de intensidade do trabalho. Variações numa ou noutra dessas dimensões acarretam, como veremos, variações proporcionais na magnitude do valor da força de trabalho. $\mathrm{Na}$ apresentação inicial que Marx faz do tema, ambas são supostas constantes. Em outras palavras, pressupõe-se uma jornada de trabalho normal e um grau de intensidade normal do trabalho. Por jornada de trabalho normal Marx entende aquela que assegura a reprodução normal (isto é, não atrofiada) da força de trabalho, tanto em seus aspectos físicos quanto morais, nas condições sociais consideradas. ${ }^{3} \mathrm{O}$ mesmo critério é válido para a intensidade do trabalho.

Em segundo lugar, a soma dos meios de subsistência deve assegurar, além da reprodução do próprio trabalhador, a de sua família:

O proprietário da força de trabalho é mortal. Se, portanto, sua aparição no mercado é para ser contínua, como pressupõe a contínua transformação de dinheiro em capital, então o vendedor da força de trabalho precisa perpetuar-se "como todo indivíduo se perpetua pela procriação”. As forças de trabalho subtraídas do mercado pelo desgaste

2 As citações de $O$ capital são indicadas pela letra $C$, seguida do livro e do tomo da obra.

3 Ver Marx (C, I/1, p. 211-212). 
e morte precisam ser continuamente substituídas ao menos por um número igual de novas forças de trabalho. A soma dos meios de subsistência necessários à produção da força de trabalho inclui, portanto, os meios de subsistência dos substitutos, isto é, dos filhos dos trabalhadores, de modo que essa race de peculiares possuidores de mercadorias se perpetue no mercado [...] $(C, \mathrm{I} / 1, \mathrm{p} .141-142)^{4}$

Em terceiro lugar, a soma dos meios de subsistência deve incluir os custos de aprendizagem (ou de desenvolvimento):

Para modificar a natureza humana geral de tal modo que ela alcance habilidade e destreza em determinado ramo de trabalho, tornando-se força de trabalho desenvolvida e específica, é preciso determinada formação ou educação, que, por sua vez, custa uma soma maior ou menor de equivalentes mercantis. Conforme o caráter mais ou menos mediato da força de trabalho, os seus custos de formação são diferentes. Esses custos de aprendizagem, ínfimos para a força de trabalho comum, entram, portanto, no âmbito dos valores gastos para a sua produção. $(C, \mathrm{I} / 1, \mathrm{p} .142)^{5}$

Assim, um aumento dos custos de aprendizagem, tudo o mais constante, tende a elevar o valor da força de trabalho, enquanto uma redução deles tende a reduzi-lo. Podemos, no entanto, por simplificação, seguir o procedimento adotado por Marx em Salário, preço e lucro: "Para o nosso objetivo, basta considerar apenas o trabalho médio, cujos gastos com educação e aperfeiçoamento são grandezas insignificantes" (MARX, 2010, p. 112).

$\mathrm{Da}$ exposição anterior, fica claro que a magnitude do valor da força de trabalho depende de dois fatores: (i) da quantidade de meios de subsistência necessários; e (ii) do valor desses meios de subsistência. A forma como Marx articula esses dois fatores em sua exposição é decisiva para a compreensão da questão da magnitude do valor da força de trabalho.

Por um lado, Marx é muito claro em afirmar que a quantidade de meios de subsistência necessários não é uma magnitude fixa. Para demonstrá-lo, argumenta que a soma dos meios de subsistência compreende tanto as necessidades naturais como as historicamente desenvolvidas (C, I/2, p. 145). E esclarece:

As próprias necessidades naturais, como alimentação, roupa, aquecimento, moradia etc., são diferentes de acordo com o clima e outras peculiaridades naturais de um país. Por outro lado, o âmbito das assim chamadas necessidades básicas, assim como o modo de sua satisfação, é ele mesmo um produto histórico e depende, por isso, grandemente do nível cultural de um país, entre outras coisas também essencialmente sob que condições, e, portanto, com que hábitos e aspirações de vida, se constituiu a classe dos tra-

\footnotetext{
4 Ver também Marx (C, I/2, p. 23) e Marx (2010, p. 111-112).
}

5 Ver também $\operatorname{Marx}(C, \mathrm{I} / 2, \mathrm{p} .113)$. 
balhadores livres. Em antítese às outras mercadorias, a determinação do valor da força de trabalho contém, por conseguinte, um elemento histórico e moral. (C, I/1, p. 141)

A massa de meios de subsistência será, portanto, diferente entre países no mesmo momento e variará no mesmo país ao longo do tempo. Em virtude disso, lemos em Salário, preço e lucro:

Ao compararmos os salários normais ou valores do trabalho em diversos países, e comparando-os em diferentes épocas históricas no mesmo país, veremos que o valor do trabalho ${ }^{6}$ não é por si uma grandeza constante, mas variável, mesmo supondo que os valores das demais mercadorias permaneçam fixos. (MARX, 2010, p. 136) ${ }^{7}$

Por outro lado, para efeito da investigação que se segue, a massa de meios de subsistência será considerada como uma magnitude fixa: "No entanto, para determinado país, em determinado período, o âmbito médio dos meios de subsistência básicos é dado” (C, I/1, p. 141). Isso está mais desenvolvido nesta outra passagem:

O valor da força de trabalho é determinado pelo valor dos meios de subsistência habitualmente necessários ao trabalhador médio. A massa desses meios de subsistência, ainda que sua forma possa variar, em determinada época de determinada sociedade é dada, podendo, portanto, ser tratada como uma grandeza constante. O que muda é o valor dessa massa. $(C, \mathrm{I} / 2$, p. 113)

A adoção desse pressuposto permite a Marx atribuir as variações no valor da força de trabalho exclusivamente a variações no valor dos meios de subsistência necessários: "O valor da força de trabalho se resolve no valor de uma soma determinada de meios de subsistência. Ele muda, portanto, também com o valor desses meios de subsistência, isto é, com a grandeza do tempo de trabalho exigido para sua produção $(C, \mathrm{I} / 1$, p. 142).

Esse é o procedimento padrão adotado por Marx em sua investigação acerca do problema que nos ocupa. Do que se trata? De um mero recurso expositivo - ou de um aspecto essencial?

$\mathrm{Na}$ verdade, esse procedimento não é arbitrário. É que Marx desenvolve sua concepção da magnitude do valor da força de trabalho em estrita coerência com sua teoria do valor. A questão a que busca responder aqui é: quanto trabalho é necessário para (re)produzir determinada quantidade dessa mercadoria especial que é a força de trabalho. ${ }^{8}$ Assim, para o propósito de determinar a magnitude do valor da

6 Em Salário, preço e lucro, por simplificação Marx se refere, às vezes, ao valor da força de trabalho como valor do trabalho.

7 A propósito, ver a crítica de Marx aos fisiocratas em Teorias da mais-valia (TMV, I, p. 20). (As citações de Teorias da mais-valia são indicadas pelas iniciais $T M V$, seguidas do volume.)

8 O caráter especial da mercadoria força de trabalho decorre, por um lado, da formação do seu valor 
força de trabalho, é necessário supor dada a massa de meios de subsistência. ${ }^{9}$ Mas é evidente que aquela magnitude pode variar conforme varie essa massa.

Nesses termos, a tarefa de identificar os fatores que explicam as variações na magnitude do valor da força de trabalho equivale a identificar os fatores que incidem, por um lado, sobre o valor e, por outro, sobre o volume dos meios de subsistência necessários. ${ }^{10} \mathrm{Um}$ fator adicional consiste na participação das forças de trabalho feminina e infantil, cujo aumento tende a rebaixar o valor da força de trabalho. ${ }^{11}$ Daqui por diante, esse fator será excluído, e a investigação se concentrará nos fatores que incidem sobre o valor e o volume dos meios de subsistência.

Variações no valor dos meios de subsistência são explicadas por variações na produtividade do trabalho. Assim, Marx escreve: "O valor das mercadorias está na razão inversa da força produtiva do trabalho. Do mesmo modo, por ser determinado por valores de mercadorias, o valor da força de trabalho" (C, I/1, p. 253). Trata-se da produtividade não no ramo particular em que o trabalhador exerce sua atividade, mas nos ramos que produzem os meios de subsistência necessários, assim como naqueles que fornecem meios de produção aos primeiros $(C, \mathrm{I} / 1, \mathrm{p} .251)$. Um aumento da produtividade nesses ramos tem o efeito de reduzir a parte da jornada de trabalho durante a qual o trabalhador produz um equivalente ao valor dos seus meios de subsistência. ${ }^{12}$

Se as variações na magnitude do valor da força de trabalho associadas a variações na produtividade do trabalho são admitidas sem maiores dificuldades pelos intérpretes, o mesmo não pode ser dito das variações relacionadas a variações no volume dos meios de subsistência. Deixando de lado as interpretações que sequer levam em conta essas variações, ou seja, que consideram um volume invariável de meios de subsistência, a discussão da questão pode ser dividida em duas partes.

a partir dos elementos físico e histórico-moral; por outro, da existência de "um limite de seu consumo pelo comprador" (C, I/1, p. 190).

9 Isso fica claro também na seguinte passagem de Teorias da mais-valia: "[...] constitui fundamento da economia moderna, envolvida com a análise da produção capitalista, considerar o valor da força de trabalho algo fixo, magnitude dada, o que ele é na prática em cada caso particular" (TMV, I, p. 20).

10 No início do capítulo 20 do livro I de O capital ("Diversidade nacional dos salários”), Marx elenca os fatores que incidem sobre a magnitude do valor da força de trabalho de forma distinta da que propomos aqui. Ver Marx (C, I/2, p. 145).

11 "A utilização dessas diferentes forças de trabalho, por sua vez condicionada pelo modo de produção, acarreta grande diferença nos custos de reprodução da família trabalhadora e no valor do trabalhador masculino adulto" (MARX, C, I/2, p. 113).

12 "O trabalhador individual, para repor seu salário, por certo não produz diretamente os produtos de que vive, mas produz mercadorias no valor de seus meios de subsistência ou produz o valor de seus meios de subsistência, ou antes, reproduz esse valor, se consideramos a continuidade desse processo. [...] Depende do valor desses meios de subsistência (isto é, da produtividade social do trabalho e não da produtividade do ramo particular onde trabalha) o tamanbo que terá o segmento de sua jornada destinado a reproduzir ou produzir o valor, ou seja, o equivalente de seus meios de subsistência” (MARX, TMV, II, p. 836-837). Ver também p. 849. 
i) Considerando os meios de subsistência habituais da classe trabalhadora, o volume desses meios pode variar em decorrência de variações na duração ou na intensidade do trabalho. Elevações na magnitude extensiva ou intensiva do trabalho produzirão, tudo o mais constante (em especial, a produtividade do trabalho), ${ }^{13}$ elevações correspondentes no valor da força de trabalho, ao elevarem a massa de meios de subsistência necessários, de modo a fazer face ao maior desgaste envolvido. ${ }^{14}$

ii) Considerando dadas a duração e a intensidade do trabalho, o volume dos meios de subsistência pode variar em decorrência da incorporação de novas necessidades à cesta de consumo do trabalhador. Novamente considerando tudo o mais constante, o valor da força de trabalho deverá elevar-se.

Resta acrescentar que são possíveis diversos resultados do funcionamento desses mecanismos. Aumentos do volume dos meios de subsistência podem ocorrer simultaneamente a uma redução do seu valor, graças a aumentos da produtividade do trabalho, de modo que o valor da força de trabalho pode terminar aumentando menos que proporcionalmente ao aumento do volume desses meios.

\section{Sobre a categoria preço da força de trabalho}

Em primeira instância, o preço da força de trabalho nada mais é que o valor da força de trabalho expresso em dinheiro. Consideremos o seguinte exemplo:

Supondo-se que 6 horas de trabalho social estão contidas nessa massa de mercadorias necessária ao dia médio, então se objetiva diariamente na força de trabalho meio dia de trabalho social médio, ou meio dia de trabalho é exigido para a produção diária da força de trabalho. Esse quantum de trabalho exigido para sua produção diária forma o valor de um dia de força de trabalho ou o valor da força de trabalho reproduzida em um dia. Se meio dia de trabalho social médio se representa igualmente numa massa de ouro de 3 xelins ou em 1 táler, então 1 táler é o preço correspondente ao valor de um dia da força de trabalho. Se o possuidor da força de trabalho oferece-a por 1 táler ao dia, então o seu preço de venda é igual ao seu valor e, de acordo com nossos pressupostos, o possuidor de dinheiro, que cobiça transformar o seu táler em capital, paga esse valor. (C, I/1, p. 142)

13 Com um aumento da produtividade, o aumento do valor da força de trabalho pode ser menos que proporcional ao aumento da jornada ou da intensidade do trabalho.

14 Esse ponto é aceito por diferentes intérpretes de Marx. Por exemplo, Grossmann (1979, p. 382): "Os custos de reprodução não são constantes e Marx ilustra como os custos de reprodução da força de trabalho devem necessariamente aumentar, conforme a jornada de trabalho cresça em extensão [...] ou em intensidade”. Acerca do aumento da intensidade, Mandel (1985, p. 67) afirma: “[...] o valor da força de trabalho é uma categoria objetiva. Isso implica, entre outros fenômenos, que um incremento importante na intensidade do processo de trabalho leva a um incremento no valor da força de trabalho se tudo o mais permanece constante. Um gasto maior da força de trabalho implica a necessidade de um maior consumo, por exemplo, comida de maior conteúdo calórico para evitar a erosão da capacidade de trabalho". 
Trata-se, como se vê, do preço correspondente ao valor da força de trabalho. Ou seja, na situação descrita, existe uma correspondência quantitativa entre o preço (forma relativa do valor) e a magnitude do valor (quantidade de trabalho objetivado na mercadoria força de trabalho). Novamente Marx aplica ao caso da mercadoria força de trabalho o mesmo procedimento adotado para as demais mercadorias. Advirta-se desde já que tal correspondência entre preço e valor será abandonada posteriormente. Trata-se, no entanto, de um ponto de partida necessário.

Como se sabe, esse procedimento é essencial a Marx para deixar claro que o surgimento da mais-valia deve ser explicado em estrita observância do valor da força de trabalho, e não a partir de uma violação deste. Assim, referindo-se à possibilidade de pagamento de um salário ${ }^{15}$ inferior ao valor da força de trabalho, adverte: "Apesar do papel importante que esse método desempenha no movimento real do salário, ele é aqui excluído pelo pressuposto de que as mercadorias, inclusive, portanto, a força de trabalho, sejam compradas e vendidas por seu pleno valor" (C, I/1, p. 250).

Sob o pressuposto adotado, variações no preço da força de trabalho simplesmente traduzem variações no seu valor. Não se devem a eventuais desequilíbrios do mercado de trabalho, e sim a aumentos ou reduções do próprio valor da força de trabalho, por sua vez decorrentes de mudança nos fatores identificados na seção precedente. Tudo isso serve para deixar claro que o preço-valor da força de trabalho não é influenciado pela situação do mercado de trabalho ${ }^{16} \mathrm{e}$, portanto, pelos fatores que influenciam a demanda e a oferta de força de trabalho. Antes, supõe-se aqui que essas duas forças se compensem: "Se procura e oferta se cobrem, anula-se o efeito de ambas e o salário é igual ao valor da força de trabalho" (C, III/1, p. 267).

O preço correspondente ao valor da força de trabalho é aquele que assegura a reprodução normal da força de trabalho:

O limite último ou limite mínimo do valor da força de trabalho é constituído pelo valor de uma massa de mercadorias sem cujo suprimento diário o portador da força de trabalho, o homem, não pode renovar o seu processo de vida, sendo, portanto, o valor dos meios de subsistência fisicamente indispensáveis. Se o preço da força de trabalho baixa a esse mínimo, então ele cai abaixo do valor dela, pois assim ela só pode manter-se e desenvolver-se em forma atrofiada. Mas o valor de cada mercadoria é determinado pelo tempo de trabalho requerido para fornecê-la com sua qualidade normal. (C, I/1, p. 143)

15 Existe uma diferença de fundo entre a forma salário e a categoria preço da força de trabalho. É que, enquanto a segunda é a expressão do valor da força de trabalho, o salário aparece como preço ou valor do trabalbo. Ou seja, na superfície da sociedade burguesa, através da forma salário, o valor da força de trabalho se transforma em valor do trabalho e o preço da força de trabalho, em preço do trabalho, formas carentes de sentido, mas indispensáveis à reprodução da referida sociedade (MARX, C, I/2, p. 127 e 130).

16 "O seu valor, como o de qualquer outra mercadoria, estava determinado antes de ela entrar em circulação, pois determinado quantum de trabalho social havia sido gasto para a produção da força de trabalho [...]" (MARX, C, I/1, p. 143). 
Existe, entretanto, do mesmo modo que para as demais mercadorias, a possibilidade de divergência entre o preço da força de trabalho e a magnitude do seu valor, ainda sob o pressuposto de equilíbrio do mercado de trabalho (demanda = oferta). É possível que a quantidade de trabalho necessária para reproduzir a força de trabalho permaneça invariável e, no entanto, o preço da força de trabalho aumente ou diminua, devido a uma alteração no valor do dinheiro. ${ }^{17}$ Em nosso caso, esse fator não será levado em conta.

\section{Os movimentos do preço da força de trabalho}

Até aqui, o preço da força de trabalho é apenas a expressão do valor dessa mercadoria em dinheiro. Em um nível de abstração relativamente elevado, a suposição de correspondência quantitativa entre ambos é suficiente, permitindo, como vimos, extrair conclusões importantes para a investigação. No entanto, o verdadeiro preço de mercado da força de trabalho ${ }^{18}$ não coincide necessariamente com o seu valor, podendo situar-se acima ou (mais frequentemente) abaixo dele. Para levar em consideração esse aspecto, é necessário que a investigação se faça num nível de abstração menor que o anterior, incorporando os fenômenos que ocorrem no âmbito do mercado de trabalho.

A posição de Marx acerca do papel do mercado de trabalho é clara. Variações na relação entre demanda e oferta podem explicar apenas variações no preço de mercado da força de trabalho, mas, em hipótese alguma, no próprio valor dessa mercadoria. Antes, o valor da força de trabalho constitui o eixo em torno do qual gravitam seus preços de mercado.

17 Marx considera essa possibilidade em Salário, preço e lucro: "Os valores dos artigos de primeira necessidade e, por conseguinte, o valor do trabalho podem permanecer invariáveis, mas o preço desses artigos em dinheiro pode sofrer alteração, desde que haja uma prévia modificação no valor do dinheiro. Com a descoberta de jazidas mais férteis etc., a produção de 2 onças de ouro, por exemplo, não demandaria mais trabalho do que antes exigia a produção de uma onça. Neste caso, o valor do ouro baixaria para metade, em 50\%. Como, em consequência, os valores das demais mercadorias seriam expressos pelo dobro do seu preço anterior em dinheiro, o mesmo aconteceria com o valor do trabalho. As 12 horas de trabalho, que antes se expressavam em 6 xelins, agora se expressariam em 12 xelins. Logo, se o salário do operário continuasse a ser de 3 xelins, em vez de subir para 6, resultaria que o preço em dinheiro do seu trabalho só corresponderia à metade do valor do seu trabalho, e seu padrão de vida pioraria assustadoramente. $\mathrm{O}$ mesmo ocorreria, em grau maior ou menor, se o seu salário subisse, mas não proporcionalmente à baixa do valor do ouro. Em tal caso, não se teria operado a menor mudança, nem nas forças produtivas do trabalho, nem na oferta e na procura, nem nos valores. Só o nome em dinheiro desses valores teria mudado" (MARX, 2010, p. 127-128).

18 Aplicamos aqui à força de trabalho a mesma terminologia utilizada por Marx para as mercadorias em geral. Ver TMV, II, p. 636. 
[...] estaremos completamente enganados ao acreditar que o valor do trabalho ou de qualquer outra mercadoria é, em última instância, determinado pela oferta e pela procura. A oferta e a procura regulam apenas as variações temporárias dos preços de mercado. Explicam-nos por que o preço de mercado de uma mercadoria sobe acima ou cai abaixo do seu valor, mas nunca podem explicar o próprio valor. (MARX, 2010, p. 94)

Uma consequência desse ponto de vista é que os fatores que interferem na demanda e na oferta de força de trabalho não podem afetar o valor da força de trabalho. Um exame detalhado desses fatores ultrapassaria o objetivo deste trabalho, de modo que nos limitaremos a expor alguns aspectos essenciais ao tratamento das questões definidas ao princípio.

O contexto geral em que Marx trata a questão é o da acumulação de capital. Inicialmente, supõe constante a composição orgânica do capital, isto é, a relação entre o seu componente constante, convertido em meios de produção, e o seu componente variável, convertido em força de trabalho. Com esse pressuposto, a demanda de força de trabalho crescerá em proporção ao aumento do capital. É possível, inclusive, que a demanda de força de trabalho supere sua oferta, em função do que o salário pode aumentar. $\mathrm{O}$ aumento do salário, porém, tem um limite claro, qual seja, aquele que não ameace a reprodução continuada da relação capital (C, I/2, p. 187-188 e 193).

Num segundo momento, o autor supõe uma composição orgânica crescente do capital, isto é, o aumento de sua parte constante à custa de sua parte variável. "Como a demanda de trabalho não é determinada pelo volume do capital global, mas por seu componente variável, ela cai progressivamente com o crescimento do capital global, ao invés de, como antes se pressupôs, crescer de modo proporcional com ele" (C, I/2, p. 199). É verdade que esse decréscimo da demanda de força de trabalho é apenas relativo. De qualquer modo, "requer-se uma acumulação acelerada do capital global em progressão crescente para absorver um número adicional de trabalhadores de certa grandeza, ou mesmo, por causa da constante metamorfose do capital antigo, para ocupar os já em funcionamento" (ibid.). O resultado desse processo é a produção constante de uma população trabalhadora relativamente excedente para as necessidades de valorização do capital. De produto necessário da acumulação, essa superpopulação se converte em sua alavanca, na medida em que constitui um exército industrial de reserva à disposição do capital (ibid., p. 200).

A expansão do exército industrial de reserva se torna o fator decisivo na evolução do salário: "Grosso modo, os movimentos gerais do salário são exclusivamente regulados pela expansão e contração do exército industrial de reserva, que correspondem à mudança periódica do ciclo industrial” (C, I/2, p. 204). Aí temos, portanto, o principal determinante da demanda e da oferta de força de trabalho: "A superpopulação relativa é [...] o pano de fundo sobre o qual a lei da oferta e da procura de mão de obra se movimenta. Ela reduz o raio de ação dessa lei a limites absolutamente condizentes com a avidez de explorar e a paixão por dominar do capital” (ibid., p. 205). E aqui Marx esclarece que não se trata de duas forças independentes: 
A demanda de trabalho não é idêntica ao crescimento do capital, a oferta de trabalho não é idêntica ao crescimento da classe trabalhadora, como se duas potências mutuamente independentes interagissem. [...] O capital age sobre ambos os lados ao mesmo tempo. Se, por um lado, sua acumulação multiplica a demanda de trabalho, por outro multiplica a oferta de trabalhadores mediante sua "liberação", enquanto, ao mesmo tempo, a pressão dos desocupados força os ocupados a porem mais trabalho em ação, portanto, até certo ponto torna a oferta de trabalho independente da oferta de trabalhadores. O movimento da lei da demanda e oferta de trabalho completa, nessa base, o despotismo do capital. (C, I/2, p. 206, grifo nosso)

Sobre essa base, passamos a analisar os movimentos do preço da força de trabalho vis-à-vis o seu valor a propósito de dois problemas distintos.

\subsection{Luta de classes e valor da força de trabalho}

Em Salário, preço e lucro, Marx examina diversos casos em que a luta dos trabalhadores por salários constitui uma reação a movimentos anteriores do capital. A ideia geral é que, uma vez que ocorra um aumento do valor da força de trabalho, o preço da força de trabalho deve acompanhá-lo, sob pena de registrar-se uma piora nas condições de reprodução da classe trabalhadora. Ficam claras duas coisas: (i) que o aumento do preço da força de trabalho não é um processo automático, dependendo em alguma medida da combatividade da classe trabalhadora; e (ii) que a influência da luta de classes se dá em torno da fixação do preço da força de trabalho, e não do seu valor. O exemplo tomado pelo autor considera um valor da força de trabalho inicialmente igual a 6 horas, correspondentes a 3 xelins. Sendo a jornada de trabalho de 12 horas, o mais-trabalho corresponderá a 6 horas ou 3 xelins.

O primeiro caso é o de variações no valor da força de trabalho decorrentes de variações na produtividade do trabalho. A primeira passagem se refere a uma diminuição da produtividade:

Mas, vamos supor, agora, que, em consequência de uma diminuição da produtividade, seja necessário mais trabalho para produzir, digamos, a mesma quantidade de produtos agrícolas, de tal forma que o preço dos artigos diariamente necessários suba de 3 para 4 xelins. Neste caso, o valor do trabalho aumentaria de $1 / 3$, ou seja, de $33,3 \%$. Para produzir o equivalente ao sustento diário do trabalhador, dentro do padrão de vida anterior, seriam necessárias 8 horas de jornada de trabalho. Logo, o sobretrabalho diminuiria de 6 para 4 horas [...]. O trabalhador que, nessas condições, pedisse um aumento de salário estaria apenas exigindo o pagamento do valor de seu trabalho aumentado [...]. E se os salários não sobem, ou não sobem na proporção suficiente para compensar o aumento do valor dos artigos de primeira necessidade, o preço do trabalho cairá para um valor abaixo do valor do trabalho e o padrão de vida do trabalhador será pior. (MARX, 2010, p. 125-126) 
A segunda passagem se refere a um aumento da produtividade:

Com a elevação da produtividade do trabalho, pode acontecer que a mesma quantidade média de artigos de primeira necessidade, consumidos diariamente, baixe de 3 para 2 xelins, ou que, em vez de 6 horas de jornada de trabalho, sejam necessárias apenas 4 horas para produzir o equivalente do valor dos artigos de primeira necessidade consumidos num dia. O operário poderia, então, comprar por 2 xelins exatamente os mesmos artigos de primeira necessidade que antes lhe custavam 3 xelins. Na realidade, o valor do trabalho diminuiria, mas esse valor diminuído compraria a mesma quantidade de mercadorias que antes. [...] Ainda que o padrão de vida absoluto do trabalhador continuasse sendo o mesmo, seu salário relativo e, portanto, a sua posição social relativa, comparada com a do capitalista, teria piorado. Opondo-se a essa redução de seu salário relativo, o trabalhador estaria apenas lutando para obter uma parte do acréscimo das forças produtivas do seu próprio trabalho e para manter a sua antiga situação relativa na escala social. (MARX, 2010, p. 126-127)

Assim, o aumento da produtividade demarca apenas o novo limite mínimo do preço da força de trabalho. O grau efetivo de queda deste último "depende do peso relativo que a pressão do capital, de um lado, e a resistência do trabalhador, de outro, jogam no prato da balança” ( $C, \mathrm{I} / 2, \mathrm{p} .115)$.

Como se pode ver, o aumento ou a diminuição do valor da força de trabalho diante de variações na produtividade é independente da luta de classes, que tem como eixo elevar o preço da força de trabalho ao seu novo valor, na primeira situação, e impedir sua redução, na segunda.

O segundo caso é o de aumento do valor da força de trabalho decorrente de aumento da jornada de trabalho:

Ao vender a sua força de trabalho, o operário cede ao capitalista [...] o direito de empregar essa força, porém dentro de certos limites racionais. Vende a sua força de trabalho procurando conservá-la ilesa, salvo o natural desgaste, mas não para destruí-la. E como a vende pelo seu valor diário, ou semanal, subentende-se que, num dia ou numa semana, não vai submeter a sua força de trabalho a um uso, ou desgaste, de 2 dias ou 2 semanas. [...] Nas tentativas para reduzir a jornada de trabalho à sua antiga duração racional, ou - quando não podem conseguir uma fixação legal da jornada normal de trabalho - nas tentativas para compensar o trabalho excessivo por aumento de salário, aumento que não basta estar em proporção com o sobretrabalho extorquido, mas deve, sim, estar numa proporção maior, os operários cumprem apenas um dever para com eles mesmos e com os trabalhadores em geral. Limitam-se a refrear as usurpações tirânicas do capital. [...] Pode acontecer que o capitalista, ao prolongar a jornada de trabalho, pague salários mais altos e que, ao mesmo tempo, o valor do trabalho diminua, se o aumento dos salários não corresponder à maior quantidade de trabalho extorquido e ao mais rápido esgotamento da força de trabalho daí resultante. (MARX, 2010, p. 129-131) 
Assim, na medida em que a magnitude do valor da força de trabalho é definida com base numa jornada de trabalho de duração normal, o prolongamento desta última implica um aumento do valor da força de trabalho, de modo a compensar o maior desgaste dos trabalhadores. O objetivo da sua luta, nesse caso, será o de elevar o preço da força de trabalho ao seu novo valor.

O terceiro caso é o de aumento do valor da força de trabalho decorrente de aumento da intensidade do trabalho:

Mesmo com uma jornada de trabalho de limites determinados, como existe hoje em dia em todas as indústrias sujeitas à legislação sobre as fábricas, pode-se tornar necessário um aumento de salários, ainda que somente seja com o objetivo de manter o antigo nível do valor do trabalho. Pelo aumento da intensidade do trabalho, pode-se fazer um homem gastar em uma hora tanta força vital quanto antes gastaria [em] 2 horas. [...] Ao compensar essa tendência do capital pela luta por aumento de salário, correspondente ao crescimento da intensidade do trabalho, o operário resiste à depreciação do seu trabalho e à degradação de sua classe. (MARX, 2010, p. 131-132)

As implicações desse caso são semelhantes às de um aumento extensivo da jornada, no tocante ao aumento do valor da força de trabalho e à consequente luta pela elevação do preço da força de trabalho ao novo nível daquele.

Vale notar que o aumento do valor da força de trabalho, em todos os casos analisados (diminuição da produtividade, aumento da grandeza extensiva ou intensiva do trabalho), é independente da luta de classes. A diferença consiste em que, no primeiro caso, seu aumento se deve a um aumento nos valores dos meios de subsistência, enquanto nos demais casos ele se deve a um aumento na quantidade desses artigos.

O sentido geral das lutas é, portanto, o de fazer com que o preço da força de trabalho corresponda ao seu valor. ${ }^{19}$ A questão que se coloca neste ponto é a das possibilidades de êxito dos trabalhadores. Parte da resposta de Marx a essa questão consiste na dimensão do exército industrial de reserva. Com efeito, a evolução deste último constitui a base objetiva sobre a qual se desenvolve a ação da classe trabalhadora em torno da fixação do nível dos salários, definindo, portanto, as possibilidades de êxito em suas lutas por aumentos salariais ou contra a sua redução. ${ }^{20}$

Em resumo, a combatividade da classe trabalhadora, nas condições específicas da acumulação de capital e da consequente evolução do exército industrial

19 Conforme o expressa Mandel (1980, p. 153): “A coalizão operária, a supressão da concorrência entre operários, a negociação coletiva dos salários, a ação sindical, tudo isso visa, em última análise, a obter que, em média, a força de trabalho seja vendida ao seu valor, e não abaixo deste".

20 Também nesse ponto concordamos com Mandel (1980, p. 154): "Mas as possibilidades objetivas de uma ação sindical bem sucedida dependem, por sua vez, da relativa amplidão do exército de reserva industrial $[\ldots] ”$. 
de reserva, é fundamental (embora nem sempre seja o fator decisivo) ${ }^{21}$ no que diz respeito à evolução do preço da força de trabalho. Seu impacto, em todo o caso, se limita a esse plano.

Ocorre que alguns autores vão além e atribuem à luta de classes a capacidade de influenciar o próprio valor da força de trabalho. Mandel, por exemplo, argumenta em $O$ capitalismo tardio que, como o mínimo fisiológico dificilmente permite uma compressão, o elemento "variável" no valor da força de trabalho é o elemento moral ou histórico, e que a possibilidade de ampliação ou redução de necessidades do último tipo dependerá da flutuação do exército industrial de reserva e do nível alcançado pela luta de classes (MANDEL, 1982, p. 108). A partir daí, estabelece a seguinte distinção:

No curto prazo esses salários flutuam em torno do valor da força de trabalho que pode ser considerado como dado, ou correspondente a um padrão médio de vida, aceito tanto pelo capital quanto pelo trabalho. No longo prazo, o valor da mercadoria força de trabalho, afastadas flutuações no valor das mercadorias precisas para satisfazer as necessidades básicas "normais" dos trabalhadores, pode aumentar se o proletariado, no processo de aguda luta de classes, conseguir incorporar novas necessidades aos padrões de vida aceitos como normais - ou diminuir, se a burguesia for bem sucedida na eliminação de necessidades antes consideradas como normais pelos "combatentes". (MANDEL, 1982, p. 110)22

Essa interpretação parece problemática, ao colidir com toda a base da categoria valor da força de trabalho em Marx, construída, como dissemos, em observância à sua teoria do valor. Pode ser útil, a esse respeito, examinar uma passagem de Salário, preço e lucro em que Marx avalia o alcance da luta de classes. ${ }^{23} \mathrm{Ali}$, o autor

${ }^{21}$ Grossmann (1979, p. 377) observa que "em todos os países capitalistas, antes da guerra, essas 'tendências altistas' foram paralisadas, apesar do crescente poderio do proletariado e de suas organizações". Mateo também procura relativizar o alcance da combatividade da classe trabalhadora: "Não obstante, deve-se ser cauteloso em outorgar uma importância exagerada a esse fator. Note-se que Marx não faz referência a essa dimensão em $O$ capital a não ser na seção primeira do capítulo X do primeiro volume, que trata da fixação da jornada de trabalho. $\mathrm{Na}$ análise abstrata deve-se considerar uma certa combatividade da classe trabalhadora, cujo aspecto relevante é o referente objetivo que a limita, isto é, o processo de acumulação de capital, o que exclui qualquer voluntarismo idealista" (MATEO, 2007, p. 247).

22 O argumento é reafirmado em texto posterior: "A acumulação de capital implica uma queda no valor e uma expansão da produção (produção em massa) de bens de consumo não incluídos anteriormente nos custos de reprodução da força de trabalho. Se as condições objetivas e subjetivas são favoráveis, a classe trabalhadora pode forçar a inclusão desses bens no nível mínimo aceito de vida, pode expandir o componente 'histórico-moral' do valor da força de trabalho e, portanto, aumentar seu valor. Novamente, isso não sucede automaticamente, mas em essência como resultado da luta de classes" (MANDEL, 1985, p. 66).

23 A passagem em questão compreende todo o item 1 do cap. XIV da referida obra ("A luta entre o capital e o trabalho e seus resultados") (MARX, 2010, p. 133-137). 
retoma a característica que diferencia a força de trabalho das demais mercadorias, a saber, a formação do seu valor a partir de dois elementos: o físico e o histórico e social. Observa que o último elemento "pode aumentar, diminuir e, até mesmo, desaparecer completamente, de tal modo que só subsista o limite físico" (MARX, 2010, p. 135). Daí extrai a seguinte conclusão:

O capitalista tenta constantemente reduzir o salário ao seu mínimo físico e a prolongar a jornada de trabalho ao seu máximo físico, enquanto o operário exerce constantemente uma pressão no sentido contrário. A questão se reduz ao problema da relação de forças dos combatentes. (MARX, 2010, p. 136-137)

Como se pode ver, não está em questão, aí, a magnitude do valor da força de trabalho, mas apenas o nível efetivo em que se fixará o seu preço de mercado - se correspondente apenas ao mínimo físico ou a algo mais do que isso. O problema é de método: no momento de determinar a magnitude do valor da força de trabalho, considera-se uma dada cesta de bens de consumo. Assim, as únicas variações na cesta que podem ser consideradas são as decorrentes de mudança na jornada ou na intensidade do trabalho. É certo que a luta de classes pode resultar na inclusão de novas necessidades, porém isso é uma questão distinta.

Guerrero (1988) aponta a fragilidade da interpretação de Mandel. Após sustentar que a luta de classes incide exclusivamente sobre o preço da força de trabalho, determinando apenas as oscilações deste acima ou abaixo do seu valor, questiona a hipótese de redução das necessidades num contexto de refluxo da luta de classes. Com efeito - argumenta -, as necessidades são irrenunciáveis e não podem baixar de nível. É o que acontece depois de uma crise, "quando o capital consegue infligir derrotas mais ou menos importantes à classe trabalhadora, despojando-a de determinadas conquistas anteriores [...]” (p. 45). Em tal circunstância - prossegue -, as necessidades da classe trabalhadora não desaparecem ou diminuem; simplesmente ficam insatisfeitas. $\mathrm{O}$ que ocorre nesse caso não é uma queda do valor da força de trabalho, e sim uma queda do seu preço abaixo do seu valor.

A necessidade de determinação do valor da força de trabalho previamente à ação da luta de classes é apropriadamente formulada por Marini (1978, p. 68):

[...] o conceito de valor da força de trabalho é a chave para a análise da luta de classes entre trabalhadores e capitalistas, no plano econômico, os primeiros lutando por um salário que respeite esse valor, os segundos entendendo que "a gratuidade do trabalhador é um limite em sentido matemático, que nunca pode ser alcançado, embora se possa aproximar dele". ${ }^{24}$

${ }^{24}$ O trecho citado entre aspas é de Marx (C, I/2, p. 178). No original de Marini, em vez de "gratuidade", aparece "gratitud". Corrigido conforme a edição de Siglo XXI (C, I/2, 13. ed., 1987, p. 741). 
De acordo com Marini, se por um lado "a análise marxista está sempre informada pela luta de classes e remete necessariamente a ela", por outro, "em cada época da humanidade, a luta de classes se rege por leis específicas", pelo que "se torna necessário construir o instrumental teórico que nos permita explicar seu desenvolvimento" (MARINI, 1978, p. 69)..$^{25}$

\subsection{Um desvio estrutural do preço da força de trabalho com respeito ao seu valor?}

Situações em que o salário cai abaixo do valor da força de trabalho são descritas por Marx em várias ocasiões. ${ }^{26}$ Em todas elas, Marx faz questão de deixar claro (i) que, do ponto de vista do movimento real do capital, essa é uma situação que pode ser relevante para a acumulação; mas (ii) que não pode considerá-la em sua análise geral do capital, dado o nível de abstração que a caracteriza, em função do qual é adotado o pressuposto de que a mercadoria força de trabalho é comprada e vendida por seu valor.

Numa das passagens em que considera aquela possibilidade, Marx a vincula explicitamente à dimensão que assume a superpopulação relativa: “[...] na prática, o fabricante de artigos de luxo procura pagar o salário do trabalhador abaixo do valor, abaixo do mínimo, possibilidade que lhe dá a população excedente relativa, gerada pela produtividade crescente dos outros ramos industriais" (TMV, III, p. 1393).

Em resumo, em Marx o preço da força de trabalho pode situar-se abaixo do seu valor, e esse é um fenômeno que, em determinados contextos, pode ser da maior relevância para a acumulação (por exemplo, permitiria que parte do fundo de consumo do trabalhador se convertesse em fundo de acumulação de capital) $(C, \mathrm{I} / 2, \mathrm{p}$. 178). A questão que se coloca é se esse tipo de desvio é necessariamente passageiro ou se pode vir a se constituir em algo mais duradouro. Nesse caso, o não ajustamento do preço ao valor da força de trabalho não significaria uma abolição da lei do valor, no sentido de que a quantidade de trabalho necessária à produção da mercadoria força de trabalho deixaria de regular o seu valor?

Um exame detalhado dessa questão exigiria um estudo minucioso da forma como Marx relaciona, para as mercadorias em geral, a magnitude do valor e o preço

25 Osorio defende uma posição semelhante: "É sobre as bases objetivas que definem o valor da força de trabalho que se pode entender o papel do desenvolvimento da luta de classes na determinação dos salários, do mesmo modo que são a mais-valia e sua transfiguração em lucro e em lucro médio, na concorrência, os elementos-chave para compreender a disputa entre capitais. Em definitivo, não é a luta de classes que determina o valor, mas é este que define o eixo em torno do qual se desenvolverá a luta de classes" (OSORIO, 2004, p. 94).

26 Além das citadas ao longo do texto, lemos no cap. 14 do livro III de O capital, no qual se identificam algumas das contratendências à queda da taxa de lucro: "Isso [a compressão do salário abaixo do valor da força de trabalho] só se cita aqui empiricamente, já que, de fato, como várias outras coisas que deveriam ser mencionadas aqui, nada tem a ver com a análise geral do capital, mas pertence à exposição sobre a concorrência, que não é tratada nesta obra” (C, III/1, p. 179). 
de mercado, algo que não será feito aqui e sobre o qual nos limitaremos a alguns poucos aspectos, valendo-nos da interpretação de Carcanholo (2013). Nosso pressuposto é que uma relação semelhante deve ser definida para o caso da mercadoria força de trabalho.

Para as mercadorias em geral, Carcanholo (2013) desenvolve uma extensa argumentação, mostrando que não existe em Marx uma correspondência direta entre a magnitude do valor de determinada mercadoria (a quantidade de trabalho socialmente necessária à sua produção) e sua expressão no preço de mercado. Em suas palavras:

O que a teoria do valor sustenta é que, ao produzir uma unidade da mercadoria $A$, se produz um valor com magnitude determinada, independentemente do preço que se chega a estabelecer na sua venda. $\mathrm{O}$ fato de que cheguemos a supor que o preço de $A$ tende a ser proporcional à relação entre o valor de $A$ e o valor da mercadoria equivalente geral (o dinheiro) não significa afirmar que, a um preço circunstancial ou estruturalmente distinto, a magnitude do valor de $A$ não seja igual ao que tinha sido assinalado nos parágrafos anteriores [isto é, ao número de horas de trabalho socialmente necessário utilizadas em sua produção]. Pensar o contrário significa confundir o valor [...] com o valor de troca. (CARCANHOLO, 2013, p. 37)

A seguir, o autor explica o que se deve entender por correspondência entre preço e valor:

Caso o preço de $A$ realmente corresponda ao seu valor, seu produtor entra na circulação como possuidor de uma determinada magnitude de valor e sai dela com uma magnitude igual, depois de trocar sua mercadoria por dinheiro e, finalmente, este por outra mercadoria. Não ganhou nem perdeu. Se o preço de $A$ fosse superior ao correspondente ao seu valor, ao sair da órbita do mercado, o produtor dessa mercadoria possuiria um valor maior que o inicial; mas somente ganharia na circulação por ter outro produtor perdido, entregando parte de sua posse ao primeiro. (CARCANHOLO, 2013, p. 37)

Evidentemente, no caso de o preço de $A$ ser inferior ao correspondente ao seu valor, seu produtor perderia na circulação parte do valor inicial. Posto isso, Carcanholo (2013) esclarece que em nenhum momento Marx sustenta que, no regime capitalista de produção, a correspondência entre os preços de mercado e os valores possa realmente ocorrer, a não ser por pura casualidade e de forma transitória.

O ponto a destacar é que a existência de um preço de mercado diferente da magnitude do valor da mercadoria não contraria, em absoluto, a teoria do valor. Podemos nos perguntar se o mesmo pode ser dito no caso de tal divergência ser não ocasional, mas persistente. Nossa posição é que, mesmo então, a teoria do valor permanece necessária, ao estabelecer a base para a determinação da magnitude da riqueza a ser dividida.

Em relação à mercadoria força de trabalho, os desvios do preço de mercado 
com respeito ao valor poderiam ser de natureza permanente? A partir dos exemplos citados na subseção anterior, em torno do papel da luta de classes na definição do salário, é possível inferir que um contexto de fragilização da classe trabalhadora poderia acarretar a manutenção de um nível salarial inferior ao valor da força de trabalho. Ali, porém, Marx não discute a questão de até que ponto uma defasagem desse tipo poderia persistir.

Que dizer, no entanto, se a investigação se situa num nível de abstração menos elevado? Esse não seria o caso quando o objeto é o movimento do capital em formações sociais caracterizadas por relações de dependência frente aos centros dinâmicos da acumulação mundial?

Essa é a tese formulada por Marini (1973), com base na experiência das economias exportadoras latino-americanas a partir de meados do século XIX. De acordo com o autor, tais economias se inseriram na divisão internacional do trabalho então vigente na condição de exportadoras de elementos materiais que se tornariam decisivos para a mudança do eixo da acumulação de capital nos países europeus, da produção de mais-valia absoluta à de mais-valia relativa. $\mathrm{O}$ preço que tiveram de pagar por essa inserção, porém, consistiu na configuração de um tipo de desenvolvimento capitalista em que a produção de mais-valia se centrou não no incremento da força produtiva do trabalho, e sim no apelo a certos mecanismos que tinham em comum o fato de que implicavam um desvio do preço da força de trabalho com respeito ao seu valor, fenômeno que Marini denominou de superexploração. Tais mecanismos consistiam, por um lado, no aumento extensivo e intensivo do trabalho e, por outro, na redução do salário abaixo do valor da força de trabalho. Nos dois primeiros casos, a divergência entre preço e valor resultaria do fato de o aumento do valor da força de trabalho, associado ao aumento do volume de meios de subsistência necessários, não ser acompanhado de um aumento proporcional do salário. No último caso, a divergência decorreria do próprio rebaixamento do salário frente a um valor constante da força de trabalho.

Ainda segundo Marini (1973), o fenômeno da superexploração não estaria vinculado a uma etapa histórica particular do capitalismo nos países latinoamericanos, podendo, portanto, ser superado em etapas superiores desse modo de produção. Antes, corresponderia a uma característica permanente do domínio do capital nesses países. A principal explicação do autor para isso reside na importância que neles assume o exército industrial de reserva. ${ }^{27} \mathrm{~A}$ expansão deste último seria o principal fator explicativo da reduzida possibilidade de êxito da classe trabalhadora em suas reivindicações de um nível salarial que compense o desgaste anormal da força de trabalho (nos dois primeiros mecanismos) ou que assegure a manutenção do seu valor (no terceiro deles) (MARINI, 1979, p. 49-50). ${ }^{28}$

${ }^{27}$ Como se vê, Marini retoma uma relação que já se encontra no próprio Marx.

28 Há um segundo fator explicativo da possibilidade de desvio do salário do valor da força de trabalho. Trata-se do papel secundário que o consumo individual dos trabalhadores desempenhou 
Há um segundo aspecto em que o papel do exército industrial de reserva é decisivo. Retomando a concepção de Marx segundo a qual o pagamento de um salário inferior ao valor da força de trabalho implica uma reprodução atrofiada da classe trabalhadora - com a consequência de que o operário necessita ser substituído mais cedo -, é possível afirmar que a condição necessária ao pagamento de salários inferiores por longos períodos ao valor da força de trabalho é que a substituição dos trabalhadores esteja de alguma forma assegurada. Ora, argumenta Marini, esse é justamente o caso das economias latino-americanas. ${ }^{29}$

Alguns intérpretes, em contrapartida, não reconhecem a legitimidade da tese referida. Desvios do valor da força de trabalho teriam, necessariamente, caráter circunstancial e, cedo ou tarde, o preço se ajustaria ao valor. Guerrero, por exemplo, afirma:

Leve-se em conta [...] que essa queda do preço da força de trabalho abaixo de seu valor só pode ser de caráter transitório, e deve compensar-se necessariamente, portanto, com períodos nos quais ocorra, inversamente, que o preço supere o valor, de tal forma que, no longo prazo, ambos os tipos de oscilações se compensem mutuamente. Por conseguinte, equivocam-se [...] os defensores da ideia de um preço da força de trabalho permanentemente (e inclusive progressivamente) distanciado do valor da força de trabalho. (GUERRERO, 1988, p. 45) ${ }^{30}$

Do nosso ponto de vista, a admissão de um desvio persistente do salário com respeito ao valor da força de trabalho, em determinadas formações sociais, não põe em xeque a vigência da lei do valor. A questão é que aqui nos situamos num nível de abstração menor do que o adotado na investigação de Marx - o que implica que a forma como tal lei se impõe envolve maiores mediações.

\section{Conclusão}

A despeito das especificidades da mercadoria força de trabalho em relação às demais mercadorias, Marx não deixa dúvida quanto ao fato de que, na determinação da magnitude do seu valor e na relação deste último com o seu preço, prevalecem os

historicamente na realização da produção latino-americana, que em grande parte se efetuava no mercado mundial. Ver Marini (1973, p. 52).

29 " $[. .$.$] a tendência natural do sistema será a de explorar ao máximo a força de trabalho do trabalha-$ dor, sem preocupar-se em criar as condições para que este a reponha, sempre e quando se lhe possa substituir mediante a incorporação de novos braços ao processo produtivo. O dramático para a população trabalhadora da América Latina é que esse pressuposto se cumpriu amplamente: a existência de reservas de mão de obra indígena (como no México) ou os fluxos migratórios derivados do deslocamento de mão de obra europeia, provocado pelo progresso tecnológico (como na América do Sul), permitiram aumentar constantemente a massa trabalhadora, até princípios deste século" (MARINI, 1973, p. 52-53).

30 É oportuno observar que a crítica do autor tem caráter genérico, não tendo sido formulada com vistas à tese da superexploração da força de trabalho. 
mesmos princípios válidos para as demais mercadorias. A teoria do valor constitui, portanto, a referência essencial para o exame dos diferentes fatores envolvidos na determinação do valor e do preço da força de trabalho e das relações entre ambos.

Diante disso, um fator como a combatividade da classe trabalhadora pode-se revelar, em certos contextos, fundamental no sentido de evitar defasagens do preço da força de trabalho frente a aumentos do seu valor e, a fortiori, para a obtenção de um preço superior ao seu valor. No entanto, a luta de classes nada tem a ver com a determinação da magnitude do próprio valor da força de trabalho. Seus resultados afetam apenas os movimentos do preço da força de trabalho em torno do seu valor.

Um tratamento semelhante deve ser dado ao problema da defasagem estrutural entre o preço e o valor da força de trabalho. O preço pode situar-se de forma persistente abaixo do valor, como o demonstra a experiência dos países dependentes latino-americanos. Tal fato, porém, não invalida a vigência da lei do valor; apenas mostra que sua efetivação se dá de forma mais complexa do que no tipo de investigação levado a cabo por Marx.

\section{Referências}

CARCANHOLO, R. A. Capital: essência e aparência, vol. 2. São Paulo: Expressão Popular, 2013.

GROSSMANN, H. La ley de la acumulación y del derrumbe del sistema capitalista. México: Siglo XXI, 1979.

GUERRERO, D. Acumulación de capital, distribución de la renta y crisis de rentabilidad en España (1954-1987). Tese (doutorado em Economia). Universidad Complutense de Madrid, 1988. Disponível em: <http://pt.scribd.com/doc/136803967/ Guerrero-Diego-Acumulacio\%CC\%81n-de-capital-distribucio\%CC\%81n-de-la-renta-y-crisis-de-rentabilidad-en-Espan\%CC\%83a>. Acesso em: 10 mar. 2014.

MANDEL, E. A formação do pensamento econômico de Karl Marx: de 1843 até a redação de $O$ capital. 2. ed., Rio de Janeiro: Zahar, 1980.

MANDEL, E. O capitalismo tardio. São Paulo: Abril Cultural, 1982.

MANDEL, E. El capital: cien años de controversias en torno a la obra de Karl Marx. México: Siglo XXI, 1985.

MARINI, R. M. Dialéctica de la dependencia. México: Era, 1973.

MARINI, R. M. Las razones del neodesarrollismo (respuesta a F. H. Cardoso y J. Serra). Revista mexicana de sociología, número especial, p. 57-106, 1978. 
MARINI, R. M. El ciclo del capital en la economía dependiente. In: OSWALD, U. (coord.). Mercado y dependencia. México: Nueva Imagen, 1979.

MARX, K. O capital: crítica da economia política. Livro I, tomo 1. São Paulo: Abril Cultural, 1983.

MARX, K. O capital: crítica da economia política. Livro I, tomo 2. São Paulo: Abril Cultural, 1984.

MARX, K. O capital: crítica da economia política. Livro III, tomo 1. São Paulo: Abril Cultural, 1984.

MARX, K. Teorias da mais-valia: história crítica do pensamento econômico (livro 4 de $O$ capital), vol. I. São Paulo: Civilização Brasileira, 1980.

MARX, K. Teorias da mais-valia: história crítica do pensamento econômico (livro 4 de O capital), vol. II. São Paulo: DIFEL, 1983.

MARX, K. Teorias da mais-valia: história crítica do pensamento econômico (livro 4 de O capital), vol. III. São Paulo: DIFEL, 1985.

MARX, K. Salário, preço e lucro. In: . Trabalho assalariado e capital e Salário, preço e lucro. 2. ed., São Paulo: Expressão Popular, 2010.

MATEO, J. P. La tasa de ganancia en México 1970-2003: análisis de la crisis de rentabilidad a partir de la composición del capital y la distribución del ingreso. Tese (doutorado em Economia). Universidad Complutense de Madrid, 2007. Disponível em: < http://eprints.ucm.es/8126/1/T29966.pdf>. Acesso em: 08 jun. 2010.

OSORIO, J. Crítica de la economía vulgar: reproducción del capital y dependencia. México: Miguel Ángel Porrúa, Universidad Autónoma de Zacatecas, 2004. Disponível em: <http://www.estudiosdeldesarrollo.net/pagina_tipo_cuatro. php?libro=critica_de_la_economia $>$. Acesso em: 18 mar. 2010. 